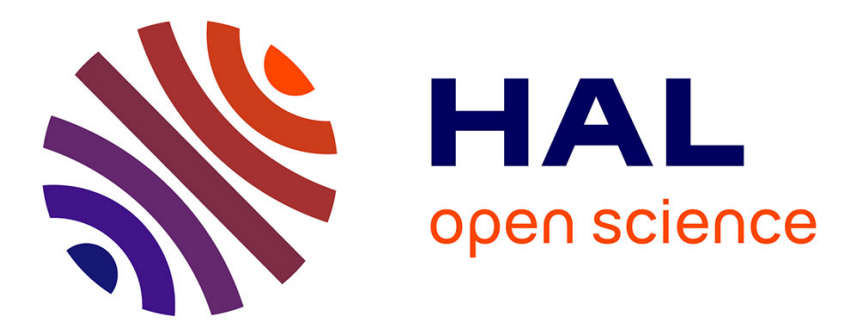

\title{
Prior sleep problems predict internalising problems later in life.
}

Evelyne Touchette, Aude Chollet, Cédric Galéra, Eric Fombonne, Bruno

Falissard, Michel Boivin, Maria Melchior

\section{> To cite this version:}

Evelyne Touchette, Aude Chollet, Cédric Galéra, Eric Fombonne, Bruno Falissard, et al.. Prior sleep problems predict internalising problems later in life.. Journal of Affective Disorders, 2012, 143 (1-3), pp.166-71. 10.1016/j.jad.2012.05.049 . inserm-00725478

\section{HAL Id: inserm-00725478 https://www.hal.inserm.fr/inserm-00725478}

Submitted on 27 Aug 2012

HAL is a multi-disciplinary open access archive for the deposit and dissemination of scientific research documents, whether they are published or not. The documents may come from teaching and research institutions in France or abroad, or from public or private research centers.
L'archive ouverte pluridisciplinaire HAL, est destinée au dépôt et à la diffusion de documents scientifiques de niveau recherche, publiés ou non, émanant des établissements d'enseignement et de recherche français ou étrangers, des laboratoires publics ou privés. 
Prior sleep problems predict internalising problems later in life

Évelyne TOUChetTE, ${ }^{\text {a,b,c }}$ Aude CHOLLET, ${ }^{\text {a,b }}$ Cédric GALÉRA, ${ }^{\text {d }}$ Eric FOMBONNE, Bruno FALISSARD, ${ }^{\mathrm{f}}$ Michel BOIVIN, ${ }^{\mathrm{c}}$ and Maria MELCHIOR ${ }^{\mathrm{a}, \mathrm{b}}$

${ }^{\text {a }}$ CESP, INSERM U1018, Epidemiology of Occupational and Social Determinants of Health, F-94807, Villejuif, France

${ }^{\mathrm{b}}$ Université de Versailles Saint-Quentin, UMRS 1018, F-94807, Villejuif, France

${ }^{\mathrm{c}}$ Groupe de Recherche en Inadaptation Psychosociale (GRIP), Laval University, School of Psychology, Canada

${ }^{\mathrm{d}}$ Université de Bordeaux, Pôle Pédopsychiatrie Universitaire, Hôpital Charles-Perrens, INSERM U897, Bordeaux, France

${ }^{\text {e }}$ McGill University, Montreal Children's Hospital, Child Psychiatry, Canada

${ }^{\mathrm{f}}$ INSERM U669, Université Paris-Sud and Université Paris-Descartes, UMR-S0669, Paris, France

(Title: 9 words; Abstract: 266 words; Main text: 2667 words;

41 references; 4 Tables, 1 Figure)

Abbreviated title: Sleep problems and internalising symptoms among youth

\section{Corresponding author}

Evelyne Touchette, $\mathrm{PhD}$

School of Psychology

Laval University

2325, rue des Bibliothèques

Québec (Québec), CANADA

Canada G1V 0A6

Phone : 418-656-2131 \#8410

Email : eveline.touchette.1@ulaval.ca 


\section{Abstract}

Background: One possible risk marker of later internalising symptoms is poor sleep, which is a problem for up to $40 \%$ of children. The present study investigated whether prior sleep problems could predict internalising symptoms over a period of 18 years of follow-up. Methods: The study sample included 1,503 French young adults from the TEMPO cohort (mean age $=28.8 \pm 3.6$ years) whose parents participate in the GAZEL cohort study. All TEMPO participants previously took part in a study of children's mental health and behaviour in 1991 (mean age $=10.3 \pm 3.6$ years) and 1999 (mean age=18.8 \pm 3.6 years). Sleep problems and internalising symptoms (depression, anxiety, somatic complaints) were assessed three times (1991, 1999, 2009) using the Achenbach System of Empirically Based Assessment (ASEBA) questionnaire. The association between sleep problems in 1991 and trajectories of internalising problems from 1991 to 2009 was tested in a multinomial logistic regression framework, controlling for sex, age, baseline temperament, behavioural problems and stressful life events, as well as family income, and parental history of depression.

Results: We identified four trajectories of internalising symptoms: high-persistent (2.5\%), high-decreasing (11.4\%), low-increasing (11.6\%), and low-persistent (74.5\%). After controlling for covariates, compared to participants who did not have sleep problems in 1991, those who did were 4.51 times $(95 \% \mathrm{CI}=1.54-13.19, \mathrm{P}=.006)$ more likely to have highpersistent internalising symptoms and 3.69 times $(95 \% \mathrm{CI}=2.00-6.82, \mathrm{P}<.001)$ more likely to have high-decreasing internalising symptoms over the 18-year follow-up.

Limitations: Sleep problems and internalising symptoms were based on self-report questions, results should be interpreted with due caution.

Conclusions: Sleep problems early in life are associated with an increased likelihood of internalising symptoms that persist from childhood to adulthood. 
Keywords: Sleep problems, depressive and anxiety symptoms, longitudinal study, epidemiology 


\section{Introduction}

Internalising problems, defined as a spectrum of symptoms of depression, anxiety, withdrawal, and somatic complaints (Achenbach et al., 1989), affect up to $40 \%$ of youth (Crawford et al., 2001). In up to 50\% of cases, these symptoms persist over time, affecting quality of life, interpersonal relationships, as well as academic and occupational attainment (Bongers et al., 2003). It is therefore important to identify youth at risk of persistent internalising symptoms in order to address their mental health needs early on and potentially prevent a long-term cycle of poor outcomes.

One possible risk marker of later internalising symptoms is poor sleep, which is a problem for up to $40 \%$ of children (Mindell et al., 1999). Although sleep problems are sometimes considered a sign of anxiety and depression (Ostberg \& Hagelin, 2011), research shows that they often precede the occurrence of other manifestations of psychological difficulties (such as excessive worry, unexplained somatic symptoms, sadness or social withdrawal). Sleep problems are associated with increased risk of internalising symptoms (particularly anxiety) in toddlers (Jansen et al., 2011), children (Pesonen et al., 2010), adolescents (Gregory \& O'Connor, 2002), and adults (Gregory et al., 2005). For instance, a longitudinal study which followed 4-19 year olds over a period of 14 years, found that various types of sleep problems, as reported by the parents using the Child Behavioural Checklist (CBCL) (e.g., "decreased sleep”, “overtiredness", and "trouble sleeping”) predicted later depression and anxiety (Gregory et al., 2008). However, to our knowledge, the relationship between sleep problems early on and trajectories of psychological difficulties has not been studied. In the present study, we examined the relationship between sleep problems measured between 4 and 16 years of age, and internalising symptoms over an 18 year follow-up period, accounting for factors which could explain this association (sex (Hankin et al., 2007), 
temperament (Touchette et al., 2005), behavioural difficulties (Silk et al., 2003), stressful life events (Eley \& Stevenson, 2000), family socioeconomic position (Arber et al., 2009), (Lorant et al., 2003; Melchior et al., 2011), and parental depression (Swanson et al., 2010).

\section{Methods}

\subsection{Study population}

The TEMPO (Trajectoires Epidémiologiques en Population) cohort study, based in France, was set up in 2009 to follow-up young adults (22-35 years) who had taken part in a study of children's psychological problems and access to mental health care in 1991. The original sample of children surveyed in 1991 (GAZEL Youth study, n=2,498) was selected among 4-16 year olds whose parents participate in the GAZEL cohort study which follows 20,624 employees of a large French public-sector utility company by yearly mailed questionnaire since 1989 (Goldberg et al., 2007). The 1991 sample of children was selected to match key characteristics of children in France (number of children per family and occupational grade of head of household) (Fombonne \& Vermeersch, 1997a, 1997b). Data on participating children were collected via parental reports. In 1999, data were collected by parental reports $(n=1,268)$ and youth self-reports $(n=1,148)$.

In 2009, all living parents of children who took part in the GAZEL Youth Study in 1991 received a letter asking them to forward the TEMPO study questionnaire to their son/daughter. Between 1991 and 2009, 16 participants died and 4 were too ill or disabled to answer. The overall response rate to the TEMPO questionnaire was $44.5 \%(\mathrm{n}=1,103)$, which is comparable to response rates of other mental health surveys in France (Alonso et al., 2004). Leading reasons for non-participation were non-transmission of the questionnaire by the parent (34.4\%) or the youth's lack of interest (28.5\%). Compared to 2009 respondents, non- 
respondents were older, more likely to have parents who were divorced, and had low socioeconomic backgroundbut did not vary with regard to their parents or their own overall psychological characteristics. The TEMPO study was reviewed and approved by an ethical board (CCTIRS: Comité Consultatif sur le Traitement des Informations pour la Recherche en Santé) and France's national committee for data protection (CNIL: Commission Nationale Informatique et Liberté).

\subsection{Outcome measures}

Participants' internalising symptoms were measured three times $(1991,1999,2009)$ using the Achenbach System of Empirically Based Assessment (ASEBA). This widely used instrument comprises 118 items which assess behaviour (internalising and externalising symptoms) over a six-month period (Achenbach, 1991). This questionnaire has previously been validated in France (Fombonne, 1991); (Stanger et al., 1994). As suggested by Gregory et al.(Gregory et al., 2011), we used the most rigorous CBCL sleep item: "Does your child have sleep problems?" which has been shown to correlate with sleep latency assessed both by diary $(\mathrm{P}=.008)$ and actigraphic measures $(\mathrm{P}=.029)$. We considered sleep problems to be present when the parents reported them "sometimes" or "often" (vs. never). In additional analyses, we used a stricter cut-off, comparing individuals who had sleep problems "often" to those who had sleep problems "sometimes" or "never". Internalising symptoms (i.e. depressive symptoms, anxiety, withdrawal, and somatic complaints) were assessed by parental reports (1991: $n=32$ items), by parental and youth self-reports combined (1999: $n=31$ items) and by young adult self-reports (2009: $n=43$ items).Each time, we excluded "sleep problems" from the items included to construct the internalising symptoms score. Internalising symptoms scores had high internal consistency at all three measurement points: Cronbach's alphas as follows: $1991=0.83,1999=0.88$, and $2009=0.93$. To estimate 
trajectories of internalising symptoms, we used continuous scores. Additionally, we also dichotomised internalising symptoms to identify participants with clinically significant symptoms levels, using the $85^{\text {th }}$ percentile score suggested by Amone-P'Olak et al.(AmoneP'Olak et al., 2009).

\subsection{Description of covariates}

In the present study, we controlled for the following covariates:

1) $\operatorname{Sex}$ (male vs. female);

2) Age (studied as a continuous variable);

3) Childhood unstable temperament, reported retrospectively for age 7-10 years by parents at time 2using the French version of the Emotionality Activity Sociability (EAS) questionnaire(Gasman et al., 2002). Unstable temperament score was defined based on answers to five items: "Cried easily?", "Was too sensitive?", "Got excited over nothing?", "Was easily upset?", and "Reacted strongly when upset?". This score was then standardized to a mean of 0 and standard deviation of 1 .

4) Initial externalizing problems (studied as a continuous variable) comprising aggressive and rule-breaking behaviours of the ASEBA questionnaire in 1991;

5) Stressful life events were measured by a combination of experiences and situations reported in 1991 (i.e., school difficulties, parental stress, childhood illness, childhood social isolation, illness of a close family member/friend, move, parental quarrels, death of a close family member/friend, parental unemployment/financial problems, parental absence from home) and parental divorce prior to age 18 as assessed based on parents' reports in the yearly GAZEL study questionnaire. We summed all stressful life events and parental divorce and studied a total score ranging from 0 to 11 ; 
6) Family socio-economic status was assessed by parent-reported family income in 1989 (dichotomized at the median value of $1,981 € /$ month) (INSEE, 2009)

7) Parental depression was assessed using two sources of information: 1) $\geq 2$ self-reports of depression in the yearly GAZEL study questionnaire (1989-2009), and 2) TEMPO participants' 2009 reports of their parents' lifetime experience of depression (yes vs. no) on the National Institute of Health-Family Inventory for Genetic Studies (NIH-FIGS) questionnaire (Maxwell, 1992).

\subsection{Statistical Analyses}

The analyses were based on 1,503 TEMPO participants who took part in at least two out of three study assessments (1991, 1999, 2009). First, we tested age and sex-adjusted concomitant associations between sleep problems and clinically significant internalising difficulties. Logistic regression models were used to test whether sleep problems in 1991 predicted the emergence of later internalising difficulties after adjusting for internalising difficulties in 1991 and the aforementioned covariates.

Next, we identified trajectories of internalising difficulties from 1991 to 2009 using a semiparametric modeling method (Nagin, 2005) implemented in SAS® (SAS Institute Inc., Cary, NC, PROC TRAJ). Based on the maximum Bayesian information criterion (BIC) the model identified four trajectories as the best fit to the data. Each individual was assigned to a specific trajectory based on a posterior probability of belonging to that group. We tested univariate associations between both sleep problems in 1991 and trajectories of internalising symptoms and all potential covariates using chi-square tests (for categorical variables), and ttests or ANOVAs (for continuous variables). 
Finally, a multinomial multivariate regression was performed to assess the association between prior sleep problems and trajectories of internalising symptoms adjusting for participants' age, sex, and all covariates associated with the presence of sleep problems in $1991 \mathrm{and} /$ or trajectories of internalising symptoms $(\mathrm{P}<0.10)$. Analyses were performed using the SPSS statistical software (version 16.0, SPSS Inc, Chicago, ILL).

\section{Results}

\subsection{Transversal analyses between sleep and internalising problems}

In the present study, $17.4 \%(\mathrm{n}=260)$ of children had sleep problems in $1991,29.9 \%$ $(n=330)$ in 1999 and $34.3 \%(n=364)$ in 2009. Restricting the definition to frequent sleep problems, prevalences were as follows: $3.7 \%(\mathrm{n}=56)$ in $1991,7.1 \%(\mathrm{n}=78)$ in 1999 and $7.5 \%$ $(\mathrm{n}=80)$ in 2009. Table 1 shows moderate age and sex-adjusted correlations between sleep problems in 1991 and internalising problems in $1991(\mathrm{r}=.18), 1999(\mathrm{r}=.17)$, and no association with internalising symptoms in 2009 ( $\mathrm{r}=.03$ ). As shown in Table 2, adjusting for internalising problems in 1991 and all covariates, sleep problems in 1991 were associated with internalising problems in $1999(\mathrm{OR}=2.18,95 \% \mathrm{CI}=1.22-3.89, \mathrm{P}=.009)$ but not in 2009 $(\mathrm{OR}=0.71,95 \% \mathrm{CI}=0.38-1.39, \mathrm{P}=.33)$

[Insert Tables 1 and 2 about here]

\subsection{Trajectories of internalising symptoms}

Figure 1 depicts trajectories of internalising symptoms between 1991 and 2009. The majority of participants $(74.5 \%, \mathrm{n}=1,119)$ had persistently low internalising symptoms throughout follow-up (persistently low trajectory). Moreover, $11.4 \%$ of participants $(\mathrm{n}=171)$ had high internalising symptoms in 1991 which decreased during follow-up (high-decreasing trajectory). In addition, $11.6 \%(\mathrm{n}=176)$ had low levels of internalising symptoms in 1991 
which increased over the course of time (low-increasing trajectory). Finally, 2.5\% of study participants $(n=37)$ had high levels of internalising symptoms throughout follow-up (highpersistent trajectory).

[Insert Figure 1 about here]

\subsection{Selection of covariates}

As shown in Table 3, sleep problems in 1991 were significantly associated with stressful life events $(\mathrm{P}<.001)$, externalizing problems $(\mathrm{P}<.001)$, an unstable temperament $(\mathrm{P}=.001)$ and parental depression $(\mathrm{P}=.01)$. Trajectories of internalising symptoms were significantly associated with participants' age $(\mathrm{P}<.001)$, sex $(\mathrm{P}<.001)$, stressful life events $(\mathrm{P}<.001)$, externalizing problems $(\mathrm{P}<.001)$, an unstable temperament $(\mathrm{P}<.001)$, and parental depression $(\mathrm{P}<.001)$, but not with family income $(\mathrm{P}=.20)$. For consistency with prior studies, family income was nevertheless controlled for.

[Insert Table 3 about here]

\subsection{Sleep problems in 1991 and trajectories of internalising symptoms}

We found an association between sleep problems in 1991 and trajectories of internalising symptoms $(\mathrm{P}<.001)$ and this association was statistically significant in female and male participants (respectively $\mathrm{P}<0.001$ and $\mathrm{P}<0.001$ ). Sleep problems in 1991 were more frequent in participants in the high-persistent (girls $=44.8 \%$, boys $=57.1 \%$ ) or high-decreasing (girls $=41.4 \%$, boys $=38.6 \%$ ) trajectories of internalising symptoms than in the low-increasing (girls $=17.5 \%$, boys $=18.0 \%)$ and low-persistent $($ girls $=14.0 \%, 11.8 \%)$ trajectories.

Associations between sleep problems and internalising symptoms trajectories did not vary with sex (interaction term not statistically significant). 
Multivariate multinomial regression models testing associations between sleep problems in 1991 and trajectories of internalising symptoms adjusting for all covariates are presented in Table 4. As expected, compared to participants with no sleep problems, those who had sleep problems in 1991 were more likely to have a high-persistent trajectory of internalising symptoms $(\mathrm{OR}=4.51,95 \% \mathrm{CI}: 1.54-13.19, \mathrm{P}=0.006)$ or a high-decreasing trajectory $(\mathrm{OR}=3.69,95 \% \mathrm{CI}=2.00-6.82, \mathrm{P}<.001)$. We found no association between sleep problems in 1991 and a low-increasing internalising symptoms trajectory $(\mathrm{P}=.89)$. Additional variables associated with the high-persistent trajectory of internalising symptoms were female sex and an unstable temperament. Additional variables associated with the high-decreasing internalising symptoms trajectory were female sex, an unstable temperament, externalizing problems, and stressful life events

[Insert Figure 2 and Table 4 about here]

\section{Discussion}

Studying a sample of young adults drawn from the community, we found that participants who had prior sleep problems had an elevated likelihood of experiencing longterm internalising problems. After accounting for important covariates, children who had sleep problems were 4.5 times more likely to have persistently high levels of internalising symptoms into young adulthood but, 3.7 times more likely to have high levels of internalising symptoms that later decreased. This association did not appear to be sex-specific; it was equivalently observed in girls and boys.

The results of the present study corroborate the predictive link between prior sleep problems and internalising problems later in life observed in previous longitudinal studies (Gregory \& O'Connor, 2002; Jansen et al., 2011). Dyssomnias, parasomnias, and short sleep duration at 18 months of age increase the risk of occurrence of depressive or anxiety 
symptoms at age 3 even after taking into account pre-existing depressive or anxiety symptoms (Jansen et al., 2011). Moreover, sleep problems at age 4 predict behavioral/emotional problems in mid-adolescence (Gregory \& O'Connor, 2002). However, we found no association between early sleep problems in 1991 and internalising problems in young adulthood, implying that internalising symptoms in adulthood have other determinants. In order to clarify the mechanisms underlying this association, future studies should focus on prior sleep problems measured objectively and mental health assessed later in life.

ASEBA measures symptoms present over the last 6 months (Achenbach, 1991). This suggests that the ASEBA may reflect trait as well as state expressions of psychopathology (Biederman et al., 2008). For example, individuals in the high-persistent internalising symptoms trajectory could indicate more a trait than a state of internalising symptoms compared with the other internalising symptoms trajectories. Different mechanisms could explain why prior sleep problems predict youths' internalising problems. First, this association could reflect common genetic influences, as suggested by a study of three hundred 8-year-old twin pairs (Gregory et al., 2006). Several physiological pathways through the monoaminergic system (serotonin, norepinephrine, and dopamine) and potentially the glutamatergic system (Hashimoto, 2009), (Willner, 1983) are involved in both sleep and emotional problems.. In addition, chronic stress induced by persistent sleep problems could affect the hypothalamic-pituitary-adrenal (HPA) axis (Buckley \& Schatzberg, 2005) and result in an unusual pattern of cortisol secretion (Feder et al., 2004), which in turn, may have an effect on higher-order regulatory systems involved in emotional regulation. Similar HPA axis deregulations have been found in humans with depression and in prenatally stressed animals, suggesting that gestational stress could increase the risk of developing internalising problems (Weinstock, 1997). Moreover, sleep problems decrease daytime vigilance (Peters et al., 2009) which is increasingly thought to be associated 
with disproportionate levels of behavioral/emotional problems (Lavigne et al., 1999; Stein et al., 2001).

Conversely, shared environmental factors seem to explain a moderate proportion of the variance in the association between sleep problems and psychological problems such as depression (Gregory et al., 2006). Particularly, inadequate parental behaviors impeding selfsoothing abilities could be implicated into both sleep-wake and emotional regulatory systems (Touchette et al, 2009). Underlying child characteristics, such as temperament, might also be involved. In the present study, unstable childhood temperament was independently associated with later internalising symptoms but did not explain the association between prior sleep problems and the emergence of internalising symptoms 8 years later.

Several methodological strengths and limitations should be mentioned. We studied a longitudinal sample of community-based children for a period of 18 years where prior sleep problems were measured independently from internalising symptoms and analyses were adjusted for pre-existing individual and familial characteristics. As in many epidemiological studies, our measure of sleep was based on a single CBCL sleep item, which is well correlated with sleep latency assessed by diary and actigraphic measures (Gregory et al., 2011). As others (Gregory et al., 2005; Gregory et al., 2008), we used parental perceptions of sleep problems, which could be different from polysomnographic sleep problems. In addition, we used ASEBA scores to assess psychological difficulties, which are less specific than psychiatric diagnoses. Nevertheless, the ASEBA system has good psychometric properties (Carter et al., 2004) and has frequently been used to screen for clinically significant depressive/anxiety problems throughout the life course. 


\section{Conclusion}

Sleep problems early in life may contribute to the development of internalising problems which persist for a significant period of life. Specifically, children with sleep problems appear vulnerable to internalising symptoms in adolescence, which sometimes persist into young adulthood. These results highlight the importance of investigating the presence of sleep problems in children, as these may be indicative of risk of long-term psychological difficulties. Future studies should explore the biological mechanisms underlying the association between sleep problems and internalising symptoms and test whether treatment of sleep problems can help contain the risk of internalising psychological difficulties later on in life. 
Table 1. Concomitant and longitudinal associations between sleep problems and clinically levels of standardized internalizing problems without including sleep items in the total score at each time of measure ( $>85$ th percentile) adjusted on participants' age and sex (TEMPO cohort, 2009, $\mathrm{n}=1503$ ).

$$
\text { Internalizing problems ( }>85 \text { th percentile) }
$$

\begin{tabular}{cccc}
$\begin{array}{c}\text { Sleep problems } \\
\text { ("Sometimes true/often true") }\end{array}$ & T1 & T2 & T3 \\
\hline T1 & $.25^{\text {*** }}$ & $.17^{* * *}$ & .03 \\
T2 & & $.27^{* * *}$ & .07 \\
T3 & & & $.33^{\text {*k* }}$ \\
\hline
\end{tabular}

***. Correlation is significant at the 0.01 level (2-tailed). 
Table 2. Logistic regression models were used to test whether sleep problems in 1991 predicted the emergence of later internalizing difficulties after adjusting for baseline internalizing difficulties and important covariates (TEMPO cohort, 2009, $\mathrm{n}=1503$ ).

\begin{tabular}{|c|c|c|c|c|}
\hline \multirow{3}{*}{$\begin{array}{l}\text { Sleep problems } \\
\text { ("Sometimes true/often true") }\end{array}$} & \multicolumn{4}{|c|}{ Internalizing problems ( $>85$ th percentile) } \\
\hline & \multicolumn{2}{|c|}{ T2 } & \multicolumn{2}{|l|}{$\mathrm{T} 3$} \\
\hline & $\mathrm{OR}(95 \% \mathrm{CD})$ & $\mathrm{P}$ & $\mathrm{OR}(95 \% \mathrm{CD})$ & $\mathrm{P}$ \\
\hline T1 & $2.18(1.22-3.89)$ & .009 & $0.72(0.38-1.39)$ & .33 \\
\hline $\mathrm{T} 2$ & & & $1.33(0.79-2.23)$ & .29 \\
\hline
\end{tabular}

OR means odds ratio. $95 \%$ CI means confidence intervals. 


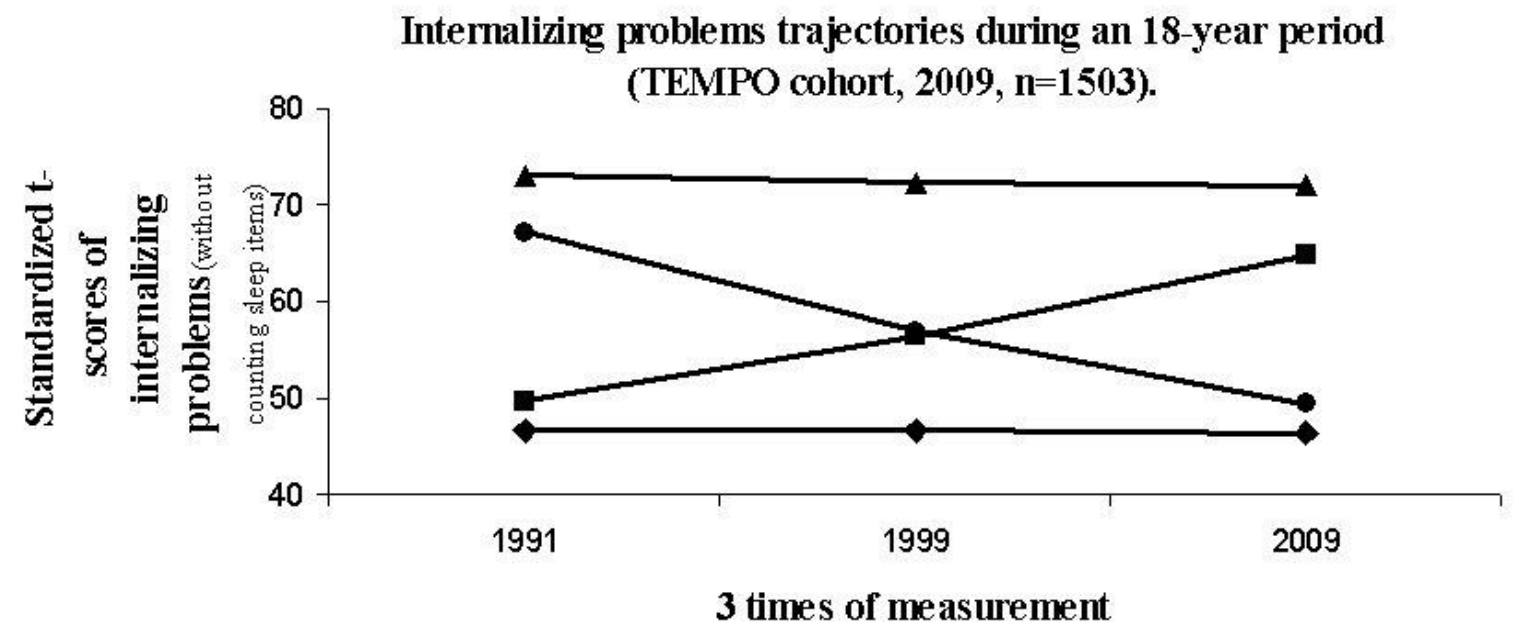

$\rightarrow$ Low-persistant internalizing problems trajectory ( $\mathrm{N}=1119,74.5 \%$ )

-High-persistant internalizing problems trajectory $(\mathrm{N}=37,2.5 \%)$

$\rightarrow$ High-decreasing intemalizing problems trajectory $(\mathrm{N}=171,11.4 \%$ )

$\rightarrow$ Low-increasing internalizing problems trajectory $(\mathrm{N}=176,11.6 \%)$ 
Table 3. Selected covariates and their associations with sleep problems in 1991 and trajectories of internalizing symptoms (TEMPO cohort, 2009, $\mathrm{n}=1503$ ).

\begin{tabular}{|c|c|c|c|c|c|c|c|c|c|}
\hline \multirow[b]{2}{*}{ Selected covariates } & \multirow{2}{*}{$\begin{array}{l}\text { Prevalence } \\
(n=1503)\end{array}$} & \multicolumn{2}{|c|}{ Sleep problems at time 1} & \multirow[b]{2}{*}{$P$} & \multicolumn{4}{|c|}{ Trajectories of internalizing symptoms } & \multirow[b]{2}{*}{$P$} \\
\hline & & $\begin{array}{c}\text { Yes } \\
(\mathrm{n}=260) \\
\end{array}$ & $\begin{array}{c}N_{0} \\
(n=1234) \\
\end{array}$ & & $\begin{array}{l}\text { High-P } \\
(\mathrm{n}=37)\end{array}$ & $\begin{array}{l}\text { High-D } \\
(\mathrm{n}=171) \\
\end{array}$ & $\begin{array}{c}\text { Low-I } \\
(\mathrm{n}=176)\end{array}$ & $\begin{array}{c}\text { Low-P } \\
(n=1119)\end{array}$ & \\
\hline \multicolumn{10}{|l|}{ Time 1} \\
\hline Sex, girls & $821(54.6)$ & $155(59.6)$ & $663(53.7)$ & .08 & $30(81.1)$ & $100(58.5)$ & $126(71.6)$ & $565(50.5)$ & $<.001$ \\
\hline Age $†$ & $10.4 \pm 3.6$ & $10.4 \pm 3.7$ & $10.4 \pm 3.6$ & .96 & $12.0 \pm 3.5$ & $11.3 \pm 3.6$ & $9.2 \pm 3.4$ & $10.4 \pm 3.6$ & $<.001$ \\
\hline Stressful life events $\dagger$ & $1.3 \pm 1.3$ & $1.8 \pm 1.5$ & $1.2 \pm 1.3$ & $<.001$ & $2.7 \pm 2.0$ & $2.0 \pm 1.5$ & $1.3 \pm 1.2$ & $1.2 \pm 1.3$ & $<.001$ \\
\hline Externalizing problems $\dagger$ & $49.6 \pm 9.5$ & $52.8 \pm 10.5$ & $48.8 \pm 9.0$ & $<.001$ & $58.2 \pm 15.3$ & $55.1 \pm 11.3$ & $49.1 \pm 8.7$ & $48.5 \pm 8.6$ & $<.001$ \\
\hline$<$ Median family income, $<1,981 € /$ month & $539(37.0)$ & $99(39.8)$ & $434(36.2)$ & .29 & $10(27.8)$ & $71(43.0)$ & $58(33.9)$ & $400(36.9)$ & .20 \\
\hline Unstable temperament ( $7-10 \mathrm{y}) \dagger$ & $11.0 \pm 3.8$ & $11.8 \pm 4.0$ & $10.8 \pm 3.8$ & .001 & $14.0 \pm 4.6$ & $12.7 \pm 3.7$ & $11.8 \pm 4.2$ & $10.5 \pm 3.6$ & $<.001$ \\
\hline Parental history of depression & $312(29.2)$ & $69(37.1)$ & $242(27.7)$ & .01 & $10(41.7)$ & $50(41.3)$ & $55(38.7)$ & $197(25.3)$ & $<.001$ \\
\hline
\end{tabular}

Chi-squared tests were used for categorical variables ( $\mathrm{n}, \%)$.

T-tests or ANOVAs were used for continuous variables $†$ (mean $\pm \mathrm{SD}$ ).

High-P refers to a trajectory of High-persistent internalizing symptoms; High-D refers to a trajectory of high-decreasing internalizing symptoms;

Low-I refers to a trajectory of low-increasing internalizing symptoms and Low-P refers to a trajectory of low-persistent internalizing symptoms. 
Table 4. A multivariate multinomial regression revealed the associations between sleep problems in 1991 and trajectories of internalizing symptoms after adjusting for age and sex (Model 1) and for all covariates (Model 2) (TEMPO cohort, 2009, n=1503).

\begin{tabular}{|c|c|c|c|c|c|c|c|c|c|}
\hline \multirow[b]{3}{*}{ Variables } & \multicolumn{9}{|c|}{ Trajectories of internalizing symptoms } \\
\hline & \multicolumn{3}{|c|}{ High-P $(\mathrm{n}=37,2.5 \%) \|$} & \multicolumn{3}{|c|}{ High-D (n=171, 11.4\%)\| } & \multicolumn{3}{|c|}{ Low-I $(\mathrm{n}=176,11.6 \%) \|$} \\
\hline & $\mathrm{OR}$ & $95 \% \mathrm{CI}$ & $P$ & $\mathrm{OR}$ & $95 \% \mathrm{CI}$ & $P$ & $\mathrm{OR}$ & $95 \% \mathrm{CI}$ & $P$ \\
\hline \multicolumn{10}{|l|}{ Model 1. Adjusted for age and sex } \\
\hline Sleep problems in 1991 & 5.82 & $(2.93-11.57)$ & $<.001$ & 4.49 & $(3.14-6.43)$ & $<.001$ & 1.37 & $(0.89-2.11)$ & .15 \\
\hline \multicolumn{10}{|l|}{ Model 2. Adjusted for all covariates $\ddagger$} \\
\hline Sleep problems in 1991 & 4.51 & $(1.54-13.19)$ & .006 & 3.69 & $(2.00-6.82)$ & $<.001$ & 0.95 & $(0.47-1.94)$ & .89 \\
\hline \multicolumn{10}{|l|}{ Covariates } \\
\hline Age in years $\dagger$ & 1.28 & $(1.08-1.51)$ & .004 & 1.10 & $(1.01-1.19)$ & .03 & 0.87 & $(0.81-0.94)$ & $<.001$ \\
\hline Sex, girls & 7.20 & $(1.53-33.77)$ & .01 & 2.36 & $(1.26-4.43)$ & .008 & 1.99 & $(1.16-3.42)$ & .01 \\
\hline Unstable temperament $†$ & 1.14 & $(1.00-1.30)$ & .047 & 1.12 & $(1.04-1.21)$ & .003 & 1.11 & $(1.03-1.18)$ & .003 \\
\hline Parental history of depression / No & 1.18 & $(0.38-3.69)$ & .77 & 1.58 & $(0.86-2.90)$ & .14 & 2.45 & $(1.46-4.12)$ & .001 \\
\hline Experiencing stressful life events $\dagger$ & 1.41 & $(0.99-2.01)$ & .06 & 1.27 & $(1.04-1.55)$ & .02 & 1.05 & $(0.86-1.29$ & .63 \\
\hline Externalizing problems $\dagger$ & 1.04 & $(0.97-1.10)$ & .26 & 1.05 & $(1.02-1.08)$ & .004 & 0.98 & $(0.95-1.02)$ & .31 \\
\hline$<$ Median family income & 1.44 & $(0.47-4.39)$ & .52 & 1.13 & $(0.62-2.06)$ & .70 & 1.36 & $(0.79-2.36)$ & .27 \\
\hline
\end{tabular}

$\mathrm{OR}$ : odds ratio, $95 \% \mathrm{CI}$ confidence intervals, and $\uparrow$ : continuous variables.

$\|$ compared with trajectory of individuals who reported persistently low internalizing problems ( $\mathrm{n}=1119)$.

$\ddagger$ Adjusted for age, sex, unstable temperament, parental history of depression, income status, experiencing stessful life events, externalizing problems, and median family income.

High-P refers to a trajectory of High-persistent internalizing symptoms; High-D refers to a trajectory of high-decreasing internalizing symptoms; Low-I refers to a trajectory of low-increasing internalizing symptoms and Low-P refers to a trajectory of low-persistent internalizing symptoms. 


\section{References}

Achenbach T.M., 1991. Manual for the Teacher's report form and 1991 profile Dept. of Psychiatry, University of Vermont, Burlington, Vt.

Achenbach T.M., Conners C.K., Quay H.C., Verhulst F.C., Howell C.T., 1989. Replication of empirically derived syndromes as a basis for taxonomy of child/adolescent psychopathology. Journal of Abnormal Child Psychology 17, 299-323.

Alonso J., Angermeyer M.C., Bernert S., Bruffaerts R., Brugha T.S., Bryson H., de Girolamo G., Graaf R., Demyttenaere K., Gasquet I., Haro J.M., Katz S.J., Kessler R.C., Kovess V., Lepine J.P., Ormel J., Polidori G., Russo L.J., Vilagut G., Almansa J., Arbabzadeh-Bouchez S., Autonell J., Bernal M., Buist-Bouwman M.A., Codony M., Domingo-Salvany A., Ferrer M., Joo S.S., Martinez-Alonso M., Matschinger H., Mazzi F., Morgan Z., Morosini P., Palacin C., Romera B., Taub N., Vollebergh W.A., 2004. Sampling and methods of the European Study of the Epidemiology of Mental Disorders (ESEMeD) project. Acta psychiatrica Scandinavica. Supplementum, 8-20.

Amone-P'Olak K., Burger H., Ormel J., Huisman M., Verhulst F.C., Oldehinkel A.J., 2009. Socioeconomic position and mental health problems in pre- and early-adolescents: the TRAILS study. Social Psychiatry and Psychiatric Epidemiology 44, 231-8.

Arber S., Bote M., Meadows R., 2009. Gender and socio-economic patterning of self-reported sleep problems in Britain. Social Science \& Medicine 68, 281-9.

Biederman, J., Ball, S. W., Monuteaux, M. C., Kaiser, R., \& Faraone, S. V., 2008. CBCL clinical scales discriminate ADHD youth with structured-interview derived diagnosis of oppositional defiant disorder (ODD). Journal of Attention Disorders 12, 76-82.

Bongers I.L., Koot H.M., van der Ende J., Verhulst F.C., 2003. The normative development of child and adolescent problem behavior. Jounral of Abnormal Psychology 112,17992.

Buckley T.M., Schatzberg A.F., 2005. On the interactions of the hypothalamic-pituitaryadrenal (HPA) axis and sleep: normal HPA axis activity and circadian rhythm, exemplary sleep disorders. The Journal of Clinical Endocrinology and Metabolism 90, 3106-14.

Carter A.S., Briggs-Gowan M.J., Davis N.O., 2004. Assessment of young children's socialemotional development and psychopathology: recent advances and recommendations for practice. Journal of Child Psychology and Psychiatry, and allied disciplines 45, 109-34.

Crawford T.N., Cohen P., Midlarsky E., Brook J.S., 2001. Internalizing symptoms in adolescents: Gender differences in vulnerability to parental distress and discord. Journal of research on adolescence 11, 95-118.

Eley T.C., Stevenson J., 2000. Specific life events and chronic experiences differentially associated with depression and anxiety in young twins. Journal of Abnormal Child Psychology 28, 383-94.

Feder A., Coplan J.D., Goetz R.R., Mathew S.J., Pine D.S., Dahl R.E., Ryan N.D., Greenwald S., Weissman M.M., 2004. Twenty-four-hour cortisol secretion patterns in prepubertal children with anxiety or depressive disorders. Biological Psychiatry 56, 198-204.

Fombonne E., 1991. The use of questionnaires in child psychiatry research: measuring their performance and choosing an optimal cut-off. Journal of Child Psychology and Psychiatry, and allied disciplines 32, 677-93.

Fombonne E., Vermeersch S., 1997a. [Children from the GAZEL cohort: II--motive for contact with the medical-educational system by age and sex]. Revue d'épidémiologie et de sante publique $45,107-15$. 
Fombonne E., Vermeersch S., 1997b. [Children of the GAZEL Cohort: I--Prevalence of contacts with the medico-educational system for psychological reasons, and associated factors]. Revue d'épidémiologie et de sante publique 45, 29-40.

Gasman L., Purper-Ouakil D., Michel G., Mouren-Simeoni M.C., Bouvard M., Perez-Diaz F., Jouvent R., 2002. Cross-cultural assessment of childhood temperament. A confirmatory factor analysis of the French Emotionality Activity and Sociability (EAS) questionnaire. European Child \& Adolesccent Psychiatry 11, 101-7.

Goldberg M., Leclerc A., Bonenfant S., Chastang J.F., Schmaus A., Kaniewski N., Zins M. (2007) Cohort profile: the GAZEL Cohort Study. International Journal of Epidemiology 36:32-9.

Gregory A.M., O'Connor T.G., 2002. Sleep problems in childhood: a longitudinal study of developmental change and association with behavioral problems. Journal of American Academy of Child and Adolesccent Psychiatry 41, 964-71.

Gregory A.M., Van der Ende J., Willis T.A., Verhulst F.C., 2008. Parent-reported sleep problems during development and self-reported anxiety/depression, attention problems, and aggressive behavior later in life. Archives of Pediatrics and Adolescent Medicine $162,330-5$.

Gregory A.M., Rijsdijk F.V., Dahl R.E., McGuffin P., Eley T.C., 2006. Associations between sleep problems, anxiety, and depression in twins at 8 years of age. Pediatrics 118 , 1124-32.

Gregory A.M., Caspi A., Eley T.C., Moffitt T.E., Oconnor T.G., Poulton R., 2005. Prospective longitudinal associations between persistent sleep problems in childhood and anxiety and depression disorders in adulthood. Journal of Abnormal Child Psychology 33, 157-63.

Gregory A.M., Cousins J.C., Forbes E.E., Trubnick L., Ryan N.D., Axelson D.A., Birmaher B., Sadeh A., Dahl R.E., 2011. Sleep items in the child behavior checklist: a comparison with sleep diaries, actigraphy, and polysomnography. Journal of the American Academy of Child and Adolescent Psychiatry 50, 499-507.

Hankin B.L., Mermelstein R., Roesch L., 2007. Sex differences in adolescent depression: stress exposure and reactivity models. Child Development 78, 279-95.

Hashimoto K., 2009. Emerging role of glutamate in the pathophysiology of major depressive disorder. Brain Research Reviews 61, 105-23.

Jansen P.W., Saridjan N.S., Hofman A., Jaddoe V.W., Verhulst F.C., Tiemeier H., 2011. Does disturbed sleeping precede symptoms of anxiety or depression in toddlers? The generation R study. Psychosomatic Medicine 73, 242-9.

Lavigne J.V., Arend R., Rosenbaum D., Smith A., Weissbluth M., Binns H.J., Christoffel K.K., 1999. Sleep and behavior problems among preschoolers. Journal of Developmental and Behavioral Pediatrcs 20, 164-9.

Lorant V., Kampfl D., Seghers A., Deliege D., Closon M.C., Ansseau M., 2003. Socioeconomic differences in psychiatric in-patient care. Acta Psychiatrica Scandinavica 107, 170-7.

Maxwell M.E., 1992. Manual for the Family Interview for Genetics Studies (FIGS), Clinical Neurogentics Branch, Intramural Research Program, National Institute of Mental Health. Bethesda, MD.

Melchior M., Chastang J.F., Head J., Goldberg M., Zins M., Nabi H., Younes N., 2011. Socioeconomic position predicts long-term depression trajectory: a 13-year follow-up of the GAZEL cohort study. Molecular Psychiatry. [Epub ahead of print].

Mindell J.A., Owens J.A., Carskadon M.A., 1999. Developmental features of sleep. Child and Adolesccent Psychiatric Clinics of North America 8, 695-725. 
Nagin D., 2005. Group-based modeling of development Harvard University Press, Cambridge, Mass.

Ostberg M., Hagelin E., 2011. Feeding and sleeping problems in infancy--a follow-up at early school age. Child: Care, Health and Development 37, 11-25.

Pesonen A.K., Raikkonen K., Paavonen E.J., Heinonen K., Komsi N., Lahti J., Kajantie E., Jarvenpaa A.L., Strandberg T., 2010. Sleep duration and regularity are associated with behavioral problems in 8-year-old children. Int J Behav Med 17:298-305. Peters J.D., Biggs S.N., Bauer K.M., Lushington K., Kennedy D., Martin J., Dorrian J. (2009) The sensitivity of a PDA-based psychomotor vigilance task to sleep restriction in 10-yearold girls. Journal of Sleep Research 18, 173-7.

Silk J.S., Steinberg L., Morris A.S., 2003. Adolescents' emotion regulation in daily life: links to depressive symptoms and problem behavior. Child Development 74,1869-80.

Stanger C., Fombonne E., Achenbach T.M., 1994. Epidemiological comparisons of American and French children: Parent reports of problems and competencies for ages 6-11. European Child \& Adolescent Psychiatry 3, 16-28.

Stein M.A., Mendelsohn J., Obermeyer W.H., Amromin J., Benca R., 2001. Sleep and behavior problems in school-aged children. Pediatrics 107, E60.

Swanson L.M., Flynn H.A., Wilburn K., Marcus S., Armitage R., 2010. Maternal mood and sleep in children of women at risk for perinatal depression. Archives of Women's Mental Health 13, 531-4.

Touchette E., Petit D., Tremblay R.E., Montplaisir J.Y., 2009. Risk factors and consequences of early childhood dyssomnias: New perspectives. Sleep Medicine Reviews 13, 35561.

Touchette E., Petit D., Paquet J., Boivin M., Japel C., Tremblay R.E., Montplaisir J.Y., 2005. Factors associated with fragmented sleep at night across early childhood. Archives of Pediatrics \& Adolescent Medicine 159, 242-9.

Weinstock M., 1997. Does prenatal stress impair coping and regulation of hypothalamicpituitary-adrenal axis? Neuroscience \& Biobehavioral Reviews 21, 1-10.

Willner P., 1983. Dopamine and depression: a review of recent evidence. I. Empirical studies. Brain Research 287, 211-24. 